\title{
KAJIAN KUAT TARIK BELAH PADA BETON RINGAN MEMADAT MANDIRI MENGGUNAKAN AGREGAT KASAR PECAHAN GENTENG DENGAN VARIASI KADAR VISCOCRETE
}

\author{
Antonius Mediyanto ${ }^{1)}$, Wibowo ${ }^{2)}$, Ahmad Rijal Arif Fathoni ${ }^{3)}$ \\ 1) Dosen Program Studi Teknik Sipil Fakultas Teknik Universitas Sebelas Maret \\ 2) Dosen Program Studi Teknik Sipil Fakultas Teknik Universitas Sebelas Maret \\ 3) Mahasiswa Program Studi Teknik Sipil Fakultas Teknik Universitas Sebelas Maret \\ Jl. Ir. Sutami 36 A, Kentingan Surakarta 57126, Telp (0271) 647069, Fax 662118 \\ Email : ahmadrrijal@student.uns.ac.id
}

\begin{abstract}
Nowdays, the world of construction, especially concrete, has experienced many developments, one of the concrete being developed is light-weight selfcompacting concrete. This concrete is concrete made of lightweight aggregate which is capable of self-compacting without the aid of a vibrator. Natural light aggregates are aggregates obtained from natural materials such as pumice, scoria, or tuff and artificial aggregates are aggregates made by heating materials, such as clay, light ash, slate ash, and claystone. To increase workability in lightweight concrete, the addition of viscocrete admixture is used so that fresh concrete is expected to flow easily and perform self-compaction. In this study, the split cylinder strength is observed due to the addition of viscocrete content. The viscocrete content used was $1.5 \% ; 1.75 \% ; 2 \%$; and $2.25 \%$. The test object used for the split cylinder strength test is a cylinder with a diameter of $15 \mathrm{~cm}$ and a beight of $30 \mathrm{~cm}$.
\end{abstract}

Keywords: Light weight aggregate, Light-weight self-compacting concrete, Split cylinder strength, Viscocrete, Workability

\begin{abstract}
Abstrak
Dewasa ini, dunia konstruksi khusunya beton mengalami banyak perkembangan, salah satu beton yang dikembangkan adalah beton ringan memadat mandiri (Light-weight Self Compacting Concrete). Beton ini merupakan beton yang terbuat dari agregat ringan yang mampu memadat mandiri tanpa bantuan alat penggetar (vibrator). Agregat ringan alami yaitu agregat yang diperoleh dari bahan-bahan alami seperti batu apung, skoria, atau tufa dan agregat buatan adalah agregat yang dibuat melalui proses pemanasan bahan-bahan, seperti tanah liat, abu terang, abu sabak, dan batu lempung. Untuk meningkatkan workability pada beton ringan ini maka digunakan penambahan admixture viscocrete sehingga diharapkan beton segar mudah mengalir dan melakukan pemadatan mandiri. Penelitian ini mengamati kuat tarik belah akibat penambahan kadar viscocrete. Kadar viscocrete yang digunakan ialah $1,5 \% ; 1,75 \% ; 2 \% ;$ dan $2,25 \%$. Benda uji yang digunakan untuk pengujian kuat tarik belah adalah silinder berukuran diameter $15 \mathrm{~cm}$ dan tinggi $30 \mathrm{~cm}$.
\end{abstract}

Kata Kunci: Agregat ringan, Beton ringan memadat mandiri, Kuat tarik belah, Viscocrete, Workabilitas

\section{PENDAHULUAN}

Dengan berkembangnya dunia konstruksi, teknologi beton juga mengalami perkembangan khususnya self compacting concrete (SCC). Teknologi yang dikembangkan salah satunya adalah lightweight self compacting concrete (LSCC).Beton ringan merupakan beton yang memiliki berat jenis yang lebih kecil dibandingkan dengan beton normal pada umumnya. Beton ringan digunakan untuk mengurangi beban mati suatu struktur beton. Beton beragregat ringan adalah beton yang memiliki struktur tertutup dan kepadatan tidak lebih dari $2200 \mathrm{~kg} / \mathrm{m}^{3} \mathrm{untuk}$ beton bertulang dan memiliki struktur tertutup dan kepadatan tidak lebih dari $2000 \mathrm{~kg} / \mathrm{m}^{3}$ untuk beton polos (Eurocode 2-2004).

Beton ini dituntut memiliki workability yang tinggi dengan menambahkan superplaticizer. Superplasticizer mampu membuat pasta bergerak bebas mengisi pori-pori beton. Dalam penelitian ini, superplasticizer yang digunakan adalah tipe Sika Viscocrete 8050SG. Bahan viscocrete digunakan untuk mereduksi air dan meningkatkan workability pada beton serta mencegah terlepasnya semen dan material halus lainnya pada saat beton segar berada pada tahap pengerasan.

Salah satu kelemahan beton yaitu memiliki nilai kuat tarik yang kecil jika dibandingkan kuat tekan. Kuat tarik beton berpengaruh terhadap kemampuan beton dalam mengatasi retak awal sebelum terjadinya pembebanan. Ada banyak cara untuk mengetahui nilai kuat tarik dari beton dan paling sering digunakan adalah tes pebelahan silinder (split cylinder) atau tes Brasil. 


\section{METODE PENELITIAN}

Metode penelitian yang digunakan pada penelitian ini ialah metode eksperimental untuk mengkaji kuat tarik belah yang dilakukan di Laboratorium Bahan dan Laboratorium Struktur Fakultas Teknik Universitas Sebelas Maret. Pengujian kuat tarik belah dilakukan pada beton silinder berukuran diameter $15 \mathrm{~cm}$ dan tinggi $30 \mathrm{~cm}$ dengan umur 28 hari. Variasi kadar viscocrete yang digunakan pada tiap pengujian adalah 1,5\%;1,75\%;2\%;2,25\%. Tiap variasi terdiri dari 3 sampel. Selanjutnya data hasil pengujian tersebut akan diolah menggunakan Microsoft Excel.

Tabel 1. Nama dan jumlah benda uji

\begin{tabular}{cccc}
\hline $\begin{array}{c}\text { Kadar } \\
\text { Viscocrete }\end{array}$ & $\begin{array}{c}\text { Nama } \\
\text { Benda Uji }\end{array}$ & $\begin{array}{c}\text { Umur } \\
\text { (hari) }\end{array}$ & Jumlah \\
\hline $1,5 \%$ & LSCC SV 1,5 & 28 & 3 \\
$1,75 \%$ & LSCC SV 1,75 & 28 & 3 \\
$2 \%$ & LSCC SV 2,00 & 28 & 3 \\
2,25 & LSCC SV 2,25 & 28 & 3 \\
\hline \multicolumn{3}{c}{ Total Benda Uji } \\
\hline
\end{tabular}

\section{Kuat Tarik Belah}

Salah satu kelemahan beton yaitu memiliki nilai kuat tarik yang kecil jika dibandingkan kuat tekan. Kuat tarik beton berpengaruh terhadap kemampuan beton dalam mengatasi retak awal sebelum terjadinya pembebanan. Ada banyak cara untuk mengetahui nilai kuat tarik dari beton dan paling sering digunakan adalah tes pembelahan silinder (split cylinder) atau tes Brasil.

Dalam konstruksi beton yang dipasang mendatar sering terkenabeban tegak lurus dan mengalami rekahan (splitting). Hal ini terjadi karena daya dukung beton terhadap gaya lentur tergantung pada jarak dari garis berat. Semakin jauh dari garis berat maka daya dukungnya semakin kecil.

Pengujian split cylinder meletakkan bahan uji pada arah memanjang di atas plat uji kemudian bahan uji diberi beban arah tegak lurus sepanjang bahan uji tersebut. Kuat tarik tercapai apabila benda uji terbelah dari ujung ke ujung. Tegangan tarik yang timbul sewaktu benda uji terbelah disebut sebagai split cylinder strength.

Besarnya kuat tarik belah dapat dihitung dengan rumus:

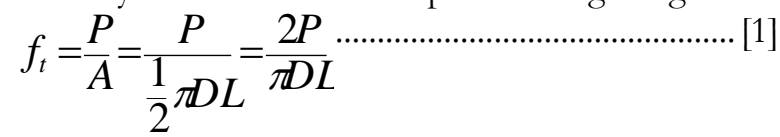

\section{Keterangan:}

$f^{\prime} t \quad=$ Kuat tarik belah beton $\left(\mathrm{N} / \mathrm{mm}^{2}\right)$ atau $(\mathrm{MPa})$

$P \quad=$ Beban yang diberikan $(\mathrm{N})$

$D \quad=$ Diameter silinder $(\mathrm{mm})$

$L \quad=$ Panjang silinder $(\mathrm{mm})$

$A \quad=$ Luas penampang $\left(\mathrm{mm}^{2}\right)$

Pengujian slump flow dengan menggunakan abrams cone ditandai dengan kemampuan beton mengalir dan mempertahankan homogenitasnya. Kemampuan mengalir ditunjukkan dengan diameter sebarandan homogenitas beton segar tergantung dari viskositas campuran, dimana dalam pengujian ini dapat dilihat dengan kecepatan aliran meskipun kecepatan aliran dipengaruhi oleh diameter sebaran.

Pengujian L-box pada beton segar menguji passingability beton. Pengujian ini dilakukan untuk mengukur kinerja beton segar mengalir melewati komponen besi penghalang dimana berat beton segar yang berada dalam kotak vertical memberikan daya dorong beton untuk melewati celah tulangan.

Pengujian $V$-funnel pada beton segar untuk menguji parameter segregation resistance beton. Pada pengujian ini dapat diketahui kemampuan beton segar mengalir ketika proses penuangan dilakukan. Cara kerja dari V-funnel adalah campuran SCC diisikan secara penuh dalam corong kemudian diamkan selama 1 menit dan pintu dibawah corong 
dibuka, kemudian hitunglah waktu kemampuan seluruh beton keluar dari V-funnel. Sedangkan cara kerja V-funnel T5 menit adalah masukkan kembali beton SCC tanpa membersihkan dinding V-funnel hasil test sebelumnya, diamkan selama 5 menit. Kemudian buka penutup bawah V-funnel dan mulailah menghitung waktu seluruh campuran beton keluar dari V-funel.

\section{HASIL DAN PEMBAHASAN}

\section{Mix Design}

Rancangan campuran adukan beton ringan memadat mandiri dengan agregat kasar pecahan genteng dengan variasi kadar viscocrete berdasarkan EFNARC 2005.

Tabel 2. Mix design

\begin{tabular}{|c|c|c|c|c|c|}
\hline Benda Uji & $\begin{array}{l}\text { Agg. Halus } \\
\left(\mathrm{Kg} / \mathrm{m}^{3}\right)\end{array}$ & $\begin{array}{l}\text { Agg. Kasar } \\
\left(\mathrm{Kg} / \mathrm{m}^{3}\right)\end{array}$ & $\begin{array}{l}\text { Semen } \\
\left(\mathrm{Kg} / \mathrm{m}^{3}\right)\end{array}$ & $\begin{array}{l}\text { Viscocrete } \\
\left(1 \mathrm{lt} / \mathrm{m}^{3}\right)\end{array}$ & $\begin{array}{l}\text { Air } \\
\left(1 \mathrm{l} / \mathrm{m}^{3}\right)\end{array}$ \\
\hline LSCC-KL-V 1,5 & 897,56 & 557,70 & 500 & 7,5 & 162,5 \\
\hline LSCC-KL-V 1,75 & 897,56 & 557,70 & 500 & 8,75 & 162,5 \\
\hline LSCC-KL-V 2 & 897,56 & 557,70 & 500 & 10 & 162,5 \\
\hline LSCC-KL-V 2,25 & 897,56 & 557,70 & 500 & 11,25 & 162,5 \\
\hline
\end{tabular}

\section{Hasil Pengujian Beton Segar}

Hasil pengujian beton segar dapat dilihat pada Tabel 3-5.

Tabel 3. Hasil pengujian slump flow

\begin{tabular}{|c|c|c|c|c|c|c|c|c|}
\hline \multirow{3}{*}{ Kode } & \multicolumn{5}{|c|}{ Flow Table Test } & \multirow{2}{*}{\multicolumn{3}{|c|}{$\begin{array}{l}\text { Syarat menurut } \\
\text { EFNARC }\end{array}$}} \\
\hline & \multicolumn{4}{|c|}{ Diameter } & \multirow{2}{*}{$\begin{array}{c}\text { Waktu } \\
t_{500} \\
(d t)\end{array}$} & & & \\
\hline & $\begin{array}{c}\mathrm{d1} \\
(\mathrm{mm})\end{array}$ & $\begin{array}{c}\mathrm{d} 2 \\
(\mathrm{~mm})\end{array}$ & $\begin{array}{c}\mathrm{d} 3 \\
(\mathrm{~mm})\end{array}$ & $\begin{array}{l}d_{\text {rata-rata }} \\
(\mathrm{mm})\end{array}$ & & $\begin{array}{l}T_{500} \\
(s)\end{array}$ & $\begin{array}{l}d_{\text {rata-rata }} \\
(\mathrm{mm})\end{array}$ & Keterangan \\
\hline $\begin{array}{l}\text { Viscocrete- } \\
1,5 \%\end{array}$ & 630 & 630 & 640 & 633,33 & 3,29 & $2-5$ & $650-800$ & $\mathbf{x}$ \\
\hline $\begin{array}{l}\text { Viscocrete- } \\
1,75 \%\end{array}$ & 640 & 640 & 660 & 646,67 & 3,09 & $2-5$ & $650-800$ & $\mathbf{x}$ \\
\hline $\begin{array}{l}\text { Viscocrete- } \\
2 \%\end{array}$ & 700 & 710 & 710 & 706,67 & 2,57 & $2-5$ & $650-800$ & $\mathbf{v}$ \\
\hline $\begin{array}{l}\text { Viscocrete- } \\
2,25 \%\end{array}$ & 700 & 700 & 740 & 713,33 & 2,15 & $2-5$ & $650-800$ & $\mathbf{v}$ \\
\hline
\end{tabular}

Keterangan $: \mathrm{v}=$ memenuhi syarat, $\mathrm{x}=$ tidak memenuhi syarat

Tabel 4. Hasil pengujian L-Box

\begin{tabular}{lccccc}
\hline \multirow{2}{*}{ Kode } & \multicolumn{5}{c}{ L-BoxType } \\
\cline { 2 - 6 } & $\begin{array}{c}\mathbf{h}_{\mathbf{1}} \\
\mathbf{( m m})\end{array}$ & $\begin{array}{c}\mathbf{h}_{\mathbf{2}} \\
\mathbf{( \mathbf { m m } )}\end{array}$ & $\mathbf{h}_{\mathbf{2}} / \mathbf{h}_{\mathbf{1}}$ & $\begin{array}{c}\text { Syarat } \\
\left(\mathbf{h}_{\mathbf{2}} / \mathbf{h}_{\mathbf{1}}\right)\end{array}$ & Keterangan \\
\hline Viscocrete-1,5\% & 7,2 & 10 & 0,72 & $0,8-1$ & $\mathrm{x}$ \\
Viscocrete-1,75\% & 7 & 9 & 0,78 & $0,8-1$ & $\mathrm{x}$ \\
Viscocrete-2\% & 6,3 & 6,9 & 0,91 & $0,8-1$ & $\mathrm{v}$ \\
Viscocrete-2,25\% & 6,2 & 6,5 & 0,95 & $0,8-1$ & $\mathrm{v}$ \\
\hline
\end{tabular}

Keterangan $: \mathrm{v}=$ memenuhi syarat, $\mathrm{x}=$ tidak memenuhi syarat

Tabel 5. Hasil pengujian $V$-funnel

\begin{tabular}{lcccc}
\hline \multicolumn{1}{c}{ Kode } & T (dt) & $\mathbf{T}_{\mathbf{5}}(\mathbf{d t})$ & Syarat $(\mathbf{d t})$ & Keterangan \\
\hline Viscocrete-1,5\% & 16,89 & 19,94 & $6-12$ & $\mathrm{x}$ \\
Viscocrete-1,75\% & 15,51 & 18,78 & $6-12$ & $\mathrm{x}$ \\
Viscocrete-2\% & 9,17 & 11,68 & $6-12$ & $\mathrm{v}$ \\
Viscocrete-2,25\% & 8,07 & 11,01 & $6-12$ & $\mathrm{v}$ \\
\hline
\end{tabular}

Keterangan $: \mathrm{v}=$ memenuhi syarat, $\mathrm{x}=$ tidak memenuhi syarat

\section{Hasil Pengujian Berat Jenis}

Berat jenis beton bergantung pada berat dan volume bahan penyusun beton tersebut. Menurut SNI 03-1969-2008 persamaan berat jenis dapat ditunjukan sebagai berikut: 


$$
\begin{aligned}
& \begin{array}{ll}
\gamma_{\text {conc }}=\frac{W(\text { bera }) t}{V(\text { volum })} \text {............................................ } \\
\text { dengan : } & \left(\mathrm{kg} / \mathrm{m}^{3}\right) \\
\gamma_{\text {conc }}=\text { Berat jenis beton } & (\mathrm{kg}) \\
\mathrm{W}=\text { Berat } & (\mathrm{m})
\end{array} \\
& \mathrm{V}=\text { Volume }\left(\mathrm{m}^{3}\right)
\end{aligned}
$$

Pengujian berat jenis beton dilakukan untuk mengetahui berat jenis masing-masing benda uji. Hasil pengujian dapat dilihat dalam Tabel 6.

Tabel 6. Hasil pengujian berat jenis beton rata-rata

\begin{tabular}{lccc}
\hline Nama Sampel & $\begin{array}{c}\text { Volume } \\
\left.\mathbf{( m}^{3}\right)\end{array}$ & $\begin{array}{c}\text { Berat } \\
\mathbf{( k g )}\end{array}$ & $\begin{array}{c}\text { Berat Jenis } \\
\mathbf{( k g / \mathbf { m } ^ { 3 } )}\end{array}$ \\
\hline LSCC VC 1,5 & 0,0053 & 10,7605 & 2018 \\
LSCC VC 1,75 & 0,0053 & 10,5820 & 2037 \\
LSCC VC 2 & 0,0053 & 10,6700 & 2026 \\
LSCC VC 2,25 & 0,0053 & 10,6200 & 2016 \\
\hline
\end{tabular}

\section{Hasil Pengujian Kuat Tarik Belah}

Pengujian kuat tarik belah beton dilakukan pada beton silinder dengan diameter $15 \mathrm{~cm}$ dan tinggi $30 \mathrm{~cm}$ dengan umur beton 28 hari. Pengujian ini dilakukan dengan menggunakan alat Compression Testing Machine (CTM). Hasil pengujian dapat dilihat pada Tabel 7.

Tabel 7. Hasil pengujian kuat tarik belah

\begin{tabular}{lcc}
\hline Nama Sampel & $\begin{array}{c}\text { Beban Uji } \\
(\mathbf{k N})\end{array}$ & $\begin{array}{c}\text { Kuat Tarik Belah } \\
(\mathbf{M P a})\end{array}$ \\
\hline LSCC VC 1,5 & 180 & 2,55 \\
LSCC VC 1,75 & 213,33 & 3,02 \\
LSCC VC 2 & 226,67 & 3,21 \\
LSCC VC 2,25 & 213,33 & 3,02 \\
\hline
\end{tabular}

\section{Hubungan Kuat Tarik Belah dengan Kuat Tekan}

Besarnya nilai kuat tarik belah berkisar antara 9\% - 15\% dari nilai kuat tekan. Hubungan kuat tarik belah dengan kuat tekan mempunyai nilai pendekatan dari hasil pengujian berulang kali mencapai 0,5 - 0,6 $\sqrt{\mathrm{fc}}$ (Dipohusodo, 1999). Hubungan yang diperoleh dalam penelitian ini dapat dilihat pada Tabel 8.

\begin{tabular}{|c|c|c|c|c|c|}
\hline Nama Sampel & $\begin{array}{c}\text { Kuat Tarik Belah }\left(\mathrm{f}^{\prime} \mathrm{t}\right) \\
(\mathrm{MPa})\end{array}$ & $\begin{array}{c}\text { Kuat Tekan (f'c) } \\
(\mathrm{MPa})\end{array}$ & $\begin{array}{c}\sqrt{ } \mathbf{f}^{\prime} \mathbf{c} \\
(\mathbf{M P a})\end{array}$ & $\begin{array}{c}K \\
\left(f^{\prime} t / \sqrt{ } f^{\prime} \mathbf{c}\right)\end{array}$ & $\begin{array}{c}\mathrm{f}^{\prime} \mathrm{t} / \mathrm{f}^{\prime} \mathrm{c} \\
(\%)\end{array}$ \\
\hline LSCC VC 1,5 & 2,55 & 22,45 & 4,74 & 0,54 & 11,34 \\
\hline LSCC VC 1,75 & 3,02 & 30,27 & 5,50 & 0,55 & 9,97 \\
\hline LSCC VC 2 & 3,21 & 27,26 & 5,22 & 0,61 & 11,76 \\
\hline LSCC VC 2,25 & 3,02 & 35,84 & 5,99 & 0,50 & 8,42 \\
\hline
\end{tabular}

Tabel 8. Hubungan kuat tarik belah dengan kuat tekan

\section{KESIMPULAN}

Dari hasil penelitian dan pembahasan yang telah diuraikan, dapat ditarik kesimpulan sebagai berikut:

1. Beton segar yang memenuhi syarat beton memadat mandiri (SCC) sesuai EFNARC 2005 yaitu pada kadar viscocrete $2,0 \%$ dan $2,25 \%$;

2. Semua beton yang dibuat pada penelitian ini mendekati standar lightweight self compacting concrete (LSCC) dengan berat jenis maksimal $2037 \mathrm{~kg} / \mathrm{m}^{3}$;

3. Penambahan kadar viscocrete dapat meningkatkan nilai kuat tarik belah. Nilai maksimum kuat tarik belah terjadi pada kadar viscocrete 2,0\% dari berat semen dengan nilai 3,2067 MPa.

\section{REKOMENDASI}


Beberapa koreksi perlu dilakukan terhadap penelitian ini agar penelitian selanjutnya dapat lebih baik. Adapun saran-saran untuk penelitian selanjutnya yaitu :

1. Membuat benda uji lebih dari yang diperlukan, sehingga hasil yang didapatkan lebih akurat dan terdapat cadangan ketika terdapat benda uji yang rusak atau dalam pengujian;

2. Perhatikan bekisting agar beton tidak mengalami kemiringan, karen bentuk beton berpengaruh pada pembacaan benda uji oleh alat uji;

3. Penelitian lebih lanjut terhadap variasi kadar viscocrete agar hasil penelitian lebih baik.

\section{UCAPAN TERIMAKASIH}

Ucapan terimakasih yang pertama diberikan kepada Allah SWT atas berkah dan rahmat-Nya selama penelitian ini berlangsung. Selanjut kepada Bapak Ir. Antonius Mediyanto, M.T., dan Wibowo, S.T., DEA selaku dosen pembimbing yang telah memberikan arahan dan masukan selama penelitian ini berlangsung. Selain itu, penulis mengucapkan terima kasih kepada kedua orang tua yang selalu mendukung dan memberikan motivasi, serta kepada staff / laboran Laboratorium Bahan Konstruksi dan Rekayasa Struktur Program Studi Teknik Sipil Fakultas Teknik Universitas Sebelas Maret Surakarta dan kepada rekan-rekan kelompok penelitian terima kasih atas bantuan dan kerja samanya.

\section{REFERENSI}

Aina, Firda., 2019, "Kajian Kuat Tekan dan Modulus Elastisitas pada Beton Ringan Memadat Mandiri Menggunakan Agregat Kasar Pecahan Genteng dengan Variasi Kadar Viscocrete", Universitas Sebelas Maret, Surakarta.

Association of Standard Testing Materials, 2006, "ASTM C494: Standard Specification for Chemical Admixture for Concrete", United States.

Astiqomah, Yuli., 2019, "Kajian Parameter Beton Ringan Memadat Mandiri Menggunakan Agregat Kasar Pecahan Genteng dengan Variasi Bahan Tambah Superplasticizer Tipe Viscacrete-8050SG", Universitas Sebelas Maret, Surakarta.

Dipohusodo, I.. 1999. "Struktur Beton Bertulang", Gramedia Pustaka Utama, Jakarta.

ERNARC, 2005, " The European Guidelines for Self-Compacting Concrete : Specification and Guidelines for Self - Compacting Concrete", European Project Group.

Eurocode 2, 2004, "Desain of Concrete Structures", Part 1-1, The European Union. 